\title{
Legal and Ethical Responsibilities Following Brain Death: The McMath and Muñoz Cases
}

Lawrence O. Gostin

Georgetown University Law Center, gostin@law.georgetown.edu

This paper can be downloaded free of charge from:

https://scholarship.law.georgetown.edu/facpub/1311

http://ssrn.com/abstract=2386042

Lawrence O. Gostin, Legal and Ethical Responsibilities Following Brain Death: The McMath and Muñoz Cases, JAMA Online (January 24, 2014), http://jama.jamanetwork.com/ article. aspx?articleid=1818922

This open-access article is brought to you by the Georgetown Law Library. Posted with permission of the author. Follow this and additional works at: https://scholarship.law.georgetown.edu/facpub

Part of the Bioethics and Medical Ethics Commons, Health Law and Policy Commons, and the Health Policy Commons 


\section{Legal and Ethical Responsibilities Following Brain Death The McMath and Muñoz Cases}

Lawrence O. Gostin, JD

O'Neill Institute for

National and Global

Health Law,

Georgetown University

Law Center,

Washington, DC.
Corresponding Author: Lawrence $\mathrm{O}$. Gostin, JD, O'Neill Institute for National and Global Health Law, Georgetown University Law Center, 600 New Jersey Ave NW,

Washington, DC 2000 (gostin@law .georgetown.edu).
Death is imbued with social, cultural, and religious meaning. From a legal and scientific perspective, however, death is a definable event. A patient's death makes it possible, even obligatory, to cease treatment and enables the harvesting of organs for transplantation to extend life for others. The clear line between life and death is important because physicians will not squander scarce medical resources or violate medical ethics by imposing treatment after the patient is dead. With a clear diagnosis, family members can also accept the death of a loved one and begin the process of mourning.

The concept of coma dépassé ("a state beyond coma") emerged in 1959, ' followed in 1968 by an ad hoc Harvard Medical School committee's classic definition of "irreversible coma as a new criterion for death." ${ }^{2}$ In 1981 , a presidential commission solidified clinical and ethical recognition of brain death defined by neurologic criteria. ${ }^{3}$

In 1981, the National Conference of Commissioners on Uniform State Laws approved the Uniform Determination of Death Act, which defined brain death consistently with the president's commission. ${ }^{4}$ All states have followed the model act, although 2 states-New Jersey and New York-require hospitals to consider the family's religious or moral views in determining a course of action after brain death. Clinicians, except in these 2 states, do not have to consult the family before withdrawing ventilation. Although state statutes do not specify clinical criteria, the medical literature has carefully described the clinical neurologic examination.

\section{Two Agonizing Brain Death Cases}

Although the clinician's clinical and ethical responsibilities following a confirmed brain death diagnosis appeared well settled, 2 evolving cases recently captured intense public attention. Physicians at Children's Hospital in Oakland, California, pronounced Jahi McMath, age 13, brain dead on December 12, 2013, but her parents obtained a temporary restraining order to prevent the hospital from withdrawing her from a ventilator. A court-appointed neurologist confirmed the diagnosis, but the court mediated an agreement to transfer Jahi to a facility that is sustaining her physiologic functions through ventilation and percutaneous endoscopic gastrostomy. ${ }^{5}$ Jahi's parents have responded in a human way-a prolonged heartbeat has led to a false hope of recovery. A beating heart is also seen as the key element for defining death in certain religious or cultural traditions. However, while medication and ventilator support can sustain a heartbeat and respiration, a beating heart is not sufficient criterion for continued life once the brain has lost all functionality.
Physicians at John Peter Smith Hospital in Fort Worth, Texas, declared Marlise Muñoz, age 33, brain dead in late November 2013 (the hospital has not confirmed the diagnosis, citing privacy concerns). At the time, the patient was 14 weeks pregnant. Respecting Ms Muñoz's wishes, her husband and parents instructed the hospital to remove her from ventilation. The hospital, however, refused to comply with the request, citing a Texas statute proscribing removal of "life sustaining treatment" from a pregnant patient. At least 31 states have similar statutes, which offer varying degrees of fetal protection. Texas is among 12 states with the most restrictive laws, which requires life support irrespective of the duration of the pregnancy. ${ }^{6}$ However, even in Texas, the law arguably would be inapplicable to Ms Muñoz because a brain-dead individual cannot, by definition, be on "life" support. Seen in this way, such laws would apply to patients in a persistent vegetative state but not those who are legally dead. Texas law, moreover, states, "the person is dead when, ... according to ordinary standards of medical practice, there is irreversible cessation of all spontaneous brain function. Death occurs when the relevant functions cease." ${ }^{7}$

In mid-January, Mr Muñoz sought a federal court order to remove his wife from the ventilator and to declare the Texas fetal protection statute unconstitutional. He claims the statute does not apply in cases of brain death, infringes his wife's right to make treatment decisions, and violates equal protection of the laws by treating pregnant women differently than other patients. ${ }^{8}$

At one level, the McMath and Muñoz cases bear striking similarity because the hospital, or the state, is defying the family's wishes. However, the cases are markedly dissimilar, with one family striving to keep their daughter on a ventilator and the other endeavoring to give the patient dignity in death. Both cases involve an attempt to protect a patient's interest (if it is possible for a deceased person to have cognizable interests). However, in one case the parents are seeking solely to safeguard the individual's interest. In the other case, the interests of the deceased woman are in conflict with those of the fetus-the abortion controversy at the opposite end of the life spectrum.

\section{Differentiating Brain Death From a Persistent} Vegetative State

The controversy surrounding life-sustaining treatment has been thoroughly examined in highly visible cases, such as Karen Ann Quinlan, Nancy Cruzan, and Terri Schiavo. Although there remains considerable disagreement on the moral and religious aspects, from a legal perspective the courts have recognized the right of patients to decline lifesustaining treatment, as well as the power of surrogates 
to express the views of once-competent patients, or to act in their best interests. This would apply both to imposing unwanted lifesustaining treatment and to discontinuing that treatment. In short, the courts have affirmed the rights to autonomy and to a dignified death, consistent with the patient's known wishes.

These cases, however, have involved individuals in a persistent vegetative state. These patients were alive, with clear interests in determining the course of their treatment. The McMath and Muñoz cases are quite distinct in that both of these individuals have been declared legally dead. Once a patient has died, any conversation about the appropriate form of medical treatment is no longer relevant. This would mean, for example, that while Jahi's mother could ask for ventilation for a short duration to enable her to come to terms with her daughter's death, the very idea of "treatment," especially if it is of an indefinite duration, would be well beyond the bounds of prevailing ethical or legal thought.

The Meaning of Autonomy

Considerable variation exists in the application of the bioethical value of autonomy. The classic understanding is that individuals have a right to determine whether they will accept medical treatment. Autonomy in this sense vindicates an individual's right of bodily integrity. Unless other interests are at stake (eg, a significant risk of transmission of an infectious disease), physicians may not impose treatment without the individual's informed consent. The law also authorizes surrogates to exercise the patient's right to decline treatment in accordance with a patient's advance directive or best interests.

This classic understanding of autonomy is often extended to the inverse case; if patients or their surrogates can decline treatment, it is argued, they can also affirmatively demand treatment-even if treatment is not clinically indicated or cost-effective. Thus, Jahi's family claims the right to ventilation and artificial nutrition for a deceased person. The family's claim implicitly requires physicians to violate their ethical responsibilities by treating a dead person.

Surrogates who assert the right to demand treatment often do so without regard to who will pay-the family, the state, or the hospital through uncompensated care. The costs of long-term hospital care, moreover, can be substantial. At the same time, the family is demanding the expenditure of inherently scarce resources, such as hospital beds, ventilators, and clinician time-resources that could be used to provide effective treatment for other patients. For these reasons, the value of autonomy should not be co-opted to permit family members to affirmatively require health professionals to provide costly treatment absent any benefit.
Whose Interests: The Woman or Her Fetus?

The claim asserted by the Muñoz family is of the more classic kind-an exercise of autonomy to protect the bodily integrity of the individual. In essence, the family is claiming the right to decline medical interventions, as expressed by the patient's former wishes. In this case, the state appears to be violating 2 interests: the individual's interest in a dignified death and burial and the physician's interest in acting ethically by not treating a dead patient.

There is a clash between the woman's clear interest in not having treatment thrust upon her and the state's interests in safeguarding the life of the fetus. How should society reconcile these 2 interests that stand in such stark tension? There are no clear answers, but only questions: when does life begin, how should it be valued, and whose choice should prevail (the woman's or the state's). The answers to these questions have seriously divided the medical and political communities and the public.

The Muñoz case has additional important features. First, at 14 weeks' gestation, the fetus would not be viable outside the womb and the woman's right to terminate the pregnancy would be constitutionally protected. Second, assuming her parents' account is accurate, Ms Muñoz is legally dead, which calls into question if the Texas statute that prohibits removal of life-sustaining treatment from a pregnant patient even applies. If it does, then the state would be instructing physicians to treat a dead patient; she has declined treatment through her surrogate. Thestate, in effect, is insisting on ventilating the woman solely to gestate the fetus. Third, given the length of time Ms Muñoz was deprived of oxygen, the continued viability of the fetus is uncertain and the fetus may have major impairments. Given her husband's feelings that his wife should not be artificially sustained, it is uncertain how he would feel about raising the infant. Should the state be able to compel treatment of a brain-dead woman in these circumstances, particularly given the husband's distress and wish to give his wife a dignified burial?

\section{A Long History of Settled Ethics and Law}

Given the extensive history of scientific, ethical, and legal understandings of patient autonomy and a dignified death, as well as the clear line between life and death, it seems surprising that the Muñoz and McMath cases have generated such interest. At one level, the outcome of these cases seems so clear-both individuals have died and they have a right to a dignified burial; and the physician's ethical responsibilities to treat are finished. At another level, the sheer symbolism of a beating heart, together with the human emotions of a loving parent or spouse, suggest that these kinds of cases at the intersection of law, ethics, and medicine will continue.

\section{ARTICLE INFORMATION}

Published Online: January 24, 2014. doi:10.1001/jama.2014.660.

Conflict of Interest Disclosures: The author has completed and submitted the ICMJE Form for Disclosure of Potential Conflicts of Interest and none were reported.

Additional Contributions: Daniel Hougendobler JD, MPH, LLM, fellow, O'Neill Institute, provided valuable research for this Viewpoint.

REFERENCES

1. Mollaret $P$, Goulon $M$. Le coma dépassé (mémoire préliminaire). Rev Neurol (Paris). 1959;101:3-5.
2. Report of the Ad Hoc Committee of the Harvard Medical School to Examine the Definition of Brain Death. A definition of irreversible coma. JAMA. 1968;205(6):337-340.

3. President's Commission for the Study of Ethica Problems in Medicine and Biomedical and Behavioral Research. Defining Death: A Report on the Medical, Legal and Ethical Issues in the Determination of Death. Washington, DC: Government Printing Office; 1981.

4. Uniform Determination of Death Act (1981). http://www.uniformlaws.org/shared/docs /determination\%20of\%20death/udda80.pdf. Accessed January 22, 2014.
5. Temporary Restraining Order, Winkfield $v$ Children's Hospital Oakland, No. RG13-707598 (Super Ct Cal, December 23, 2013)

6. Fernandez M, Eckholm E. Pregnant and forced to stay on life support. New York Times. January 8 , 2014:A1. http://www.nytimes.com/2014/01/08/us /pregnant-and-forced-to-stay-on-life-support.htm ?_r=0. Accessed January 8, 2014

7. Texas Health and Safety Code $\S 671$. http://www .statutes.legis.state.tx.us/Docs/HS/htm/HS.671.htm.

8. Fernandez M. Suing to end life support for woman and fetus. New York Times. January 15 , 2014:A14. http://www.nytimes.com/2014/01/15/us /suing-to-end-life-support-for-woman-and-fetus html. Accessed January 15, 2014. 